\title{
Alcohol, Emotion and Attention: Revisiting the Alcohol Myopia Theory
}

\author{
Álcool, Emoção e Atenção: Resgatando a Teoria da Miopia Alcoólica
}

\author{
Izabela Mocaiber, ${ }^{*}$, Isabel Antunes David ${ }^{a}$, Letícia de Oliveira ${ }^{a}$, Mirtes Garcia Pereira ${ }^{a}$, \\ Eliane Volchan ${ }^{b}$, Ivan Figueira ${ }^{b}$, Jaime Vila $^{c}, \&$ Walter Machado-Pinheiro ${ }^{a}$ \\ ${ }^{a}$ Universidade Federal Fluminense, Rio de Janeiro, Brasil \\ ${ }^{b}$ Universidade Federal do Rio de Janeiro, Rio de Janeiro, Brasil \\ $\&{ }^{c}$ Universidade de Granada, Granada, Espanha
}

\begin{abstract}
Among the known effects of alcohol on behavior, the modulation of cognitive functions (such as attention and memory), emotion, risk-taking and aggressive behavior are noteworthy. Here, we performed literature review in order to reinterpret alcohol effects on behavior according to the Alcohol Myopia Theory. According to this construct, there is a reduction of attentional resources during alcohol intoxication, which are primarily allocated to the most salient events in a given situation. The consequence is a hyperfocus directed to emotional situations when they are sufficiently relevant to grab attention, or a reduced attentional focus to emotional events in the presence of a relevant demanding task. The understanding of the mechanism mentioned above support the discussion of propositions toward the prevention of problems related to alcohol consumption. Importantly, the attentional allocation model provides inputs for a discussion on the scientifically-supported public health propositions aimed at preventing problems related to acute alcohol intoxication.

Keywords: Alcohol; Attention; Emotion; Alcohol Myopia; Context.

Resumo

Dentre os efeitos associados ao consumo alcoólico, destaca-se a modulação sobre funções cognitivas, como atenção e memória, bem como sobre as emoções, comportamento de risco e agressividade. No presente estudo apresentamos uma revisão crítica da literatura propondo uma reinterpretação para os efeitos comportamentais do álcool com base na teoria da Miopia Alcoólica. Durante a intoxicação, existiria uma redução de recursos atencionais, os quais seriam direcionados para eventos mais relevantes. A repercussão, então, seria um aumento do foco atencional para situações emocionais, quando estas fossem suficientemente relevantes ou, em contrapartida, uma diminuição para tais situações na presença de uma tarefa-alvo demandante. A reinterpretação dos efeitos do álcool, com base na teoria da Miopia Alcoólica, fornece subsídios para a mudança de paradigma na intervenção clínica.

Palavras-chave: Álcool; Atenção; Emoção; Miopia Alcoólica; Contexto.
\end{abstract}

The undesirable effects of alcohol intoxication on cognitive functions such as attention (Post, Chaderjian, \& Maddock, 2000), memory (Bartholow et al., 2003) and error detection (Casbon, Curtin, Lang, \& Patrick, 2003; Curtin, Lang, Patrick, \& Stritzke, 1998) are widely known. Among the behavioral effects, one can highlight the enhanced predisposition to risky, impulsive and aggressive behavior (George et al., 2008; Giancola \& Corman, 2007; MacDonald, MacDonald, Zanna, \& Fong, 2000; and MacDonald, Zanna, \& Fong, 1996). Nevertheless, the motivation for alcohol consumption is

\footnotetext{
"Address: Universidade Federal Fluminense, Polo Universitário de Rio das Ostras, Rua Recife, s/n, Jardim Bela Vista, Rio das Ostras, RJ, Brasil, CEP 28890-000 E-mail: mocaiber@vm uff br
}

mainly due to some of its effects on specific emotional states (Gilman, Ramchandani, Davis, Bjork, \& Hommer, 2008; Monahan \& Lannutti, 2000). One of the most desired effects is related to its anxiolytic action which can facilitate social interactions and reduce fear (Gilman et al., 2008; Herzog, 1999; and Sayette, 1993). However, because the findings of alcohol influence on affective processing are inconsistent and even incompatible, it is supposed that alcohol intoxication does not invariably decreases the emotional response but instead, its effects on emotions are possibly mediated through more complex cognitive mechanisms (Herzog, 1999; Josephs \& Steele, 1990; Steele \& Josephs, 1988, 1990). An early theory proposed by Steele and Josephs, the so-called "Alcohol Myopia", has been used by several authors in an attempt to explain the various behavioral effects of the substance 
(Josephs \& Steele, 1990; Steele \& Josephs, 1988, 1990). This theory shifts the traditional paradigm by which we understand the role that alcohol plays in emotional and behavioral states (Gilman et al., 2008; Ramchandani, Bosron, \& Li, 2001). Instead of emphasising the direct pharmacological action on some specific regions of the central nervous system, the theory supports the idea that alcohol consumption would cause a type of "myopia" by impairing the perceptual mechanisms on a contextual dependent basis (Steele \& Josephs, 1990). From this perspective, it is possible to understand how the same substance, with well known pharmacological properties and neurochemical interactions, would be associated to distinct behavioral effects. In brief, the behavioral effects of alcohol would occur as the result of excessive or almost exclusive attention paid to more relevant environmental stimuli in a given moment, thus impairing the processing of other concurrent stimuli.

Such a model has great heuristic potential as it explains one of the most intriguing aspects of alcohol's action: the variability of its effects and consequences on behavior. Therefore, Steele and Josephs (1990) illustrate in their study the immensely irregular influence of alcohol consumption on behavior, as follows:

Studies show that alcohol intoxication can make us frighteningly aggressive yet more altruistic; it can relieve stressful and anxiety and tension, yet also increase anxiety and tension; it can inflate our egos yet lead to crying-in-one's beer depression and so on.

MacAndrew and Edgerton (1969) raised the question of the variability of the alcohol effects in the following way:

... The same man, in the same bar, drinking approximately the same amount of alcohol, may, on three nights running, be, say, surly and belligerent on the first evening, the spirit of amiability on the second, and morose and withdrawn on the third. (p. 15).

The answer for the enigma of the variability of alcohol influence on the behavior, including its pleasures and harms, would be taken into account in the theory of "Alcohol Myopia". This view represents a shift of paradigm and, together with the traditional and purely pharmacological interpretations, raises the possibility of interactions between the systems related to attention and emotion regarding the effects of alcohol consumption.

The aim of the present study was to perform a literature review, focusing on the Alcohol Myopia Theory and on its meaning in order to clarify the interaction between alcohol intoxication, emotion and cognition. Such a reinterpretation has repercussions on the understanding of alcohol-related behaviors which impact on the society and public health issues. Therefore, we performed a bibliographic search for studies published between 1980 and 2008 in the Medline, LILACS, Scielo, ISI, and Cochrane databases by using the words "alcohol", "attention" and "emotion". A total of 213 studies were found and 39 articles were used in the present work as they were directly related to our theoretical purpose.

\section{Alcohol Myopia Theory}

Literature has accumulated much evidence about the effects of alcohol on social behavior and emotions, which vary widely and are highly irregular (Davis, Hendershot, George, Norris, \& Heiman, 2007; George et al., 2008; Phillips \& Giancola, 2008). Therefore, acute alcohol intoxication can both increase aggressive (Zeichner \& Pihl, 1980) and enhance altruistic (Levenson, Sher, Grossman, Newman, \& Newlin, 1980) behaviors or even reduce anxiety states (Levenson et al., 1980), among other behavioral effects. In order to explain the behavioral effects that influence the individual's social life, researchers have focused on hypotheses which were strictly based on the pharmacological and neurochemical properties of alcohol, including its role in neurotransmissior systems and neural circuits (Eckdart et al., 1998). However, the variability of alcohol effects also seems to result from an interaction between individual predispositions (i.e. expected effects, rumination and aggression traits) (Donohue, Curtin, Patrick, \& Lang, 2007; Eckdart et al., 1998; and Zeichner \& Pihl, 1980) and contextual specificity (Josephs \& Steele, 1990).

The alternate explanation to understand the alcohol effects on emotional states, which complements the pharmacological view, was proposed by Josephs and Steele, who developed an attention-allocation model capable of explaining how alcohol could affect emotional responses (Josephs \& Steele, 1990; Steele \& Josephs, 1990). The key hypothesis was that alcohol intoxication would lead to a general reduction in attentional capacity so that the remaining attentional resources would be allocated to the most relevant stimuli at each moment, depending on the contextual demands. Therefore, when fearful or threatening stimuli are processed in the presence of other relevant concurrent stimuli, the decreased attentional capacity narrowed by alcohol intoxication is directed toward the relevant stimuli and away from the stressful situation, alleviating fear. Josephs and Steele (1990) have hypothesized that alcohol influences on emotional reactions would be mediated by its effects on the attentional system, that is, at a higher cognitive level. This theory is better known as "Alcohol Myopia Theory" or "a state of shortsightedness in which we process fewer cues less well" (Steele \& Josephs, 1988).

In their classical study, Josephs and Steele (1990) have initially induced a state of anxiety in the volunteers by telling them that they should prepare and present a speech within 15 minutes. Volunteers were divided into two groups: one with alcohol ingestion and the other without alcohol ingestion. Participants' anxiety levels were evaluated at different moments by means of anxiety scales which were completed throughout the experiment. During the waiting period for the stressful event (speech 
presentation), volunteers were asked to perform two types of tasks with different difficulty levels (low and moderate). At the low level task, participants had to answer simple questions about some artistic pictures being exhibited to them. For example, they should respond whether the pictures were presented in color or black-and-white. At the moderate level task, questions demanded more elaborated answers, such as subjective opinions on the colors appearing in the pictures. There was still the situation in which the volunteers did no perform any task at all before the stressful event (speech presentation). The results revealed a reduction in anxiety levels in the group that performed the moderate-level task under alcohol intoxication. On the other hand, anxiety levels remained the same among those subjects who performed the lowlevel task under alcohol intoxication. In addition, anxiety levels increased in participants who did not perform any task during the waiting period (Josephs \& Steele, 1990).These findings suggest that alcohol seems to have reduced volunteers' attentional capacity: intoxicated individuals performing a demanding task were forced to dedicate great part of their reduced attentional resources to accuretly complete the task. In this way, a more difficult task seems to have reduced the build up of the stress reaction, thus attenuating the anxiety triggered by the iminent stressful event. Therefore, according to this theory, alcohol would consistently restrict the amount of environmental cues perceived in a given situation, and so, the amount of processed stimuli would largely depend on the contextual contingencies. In this vein, the Alcohol Myopia Theory assumes that cognitive and attentional systems play a mediator role in the behavioral effects associated to alcohol consumption.

\section{Attention and Alcohol Myopia}

Every moment, we are in contact with several stimuli from the environment. However, many of these stimuli are not adaptively important while others are essential for our adequate interaction with the environment, thus requiring a differentiated processing (Posner, 1995). Attention is a key element that allow us to enhance or decrease the cognitive processing of distinct stimuli, depending on their relevance. The observable effects of alcohol on behavior are limited when stimuli are simple and explicit or when they are presented in the absence of concurrent demands (Post et al., 2000). Nevertheless, alcohol influence becomes more clear in situations involving competition for processing resources among various stimuli (David et al., 2005).

Evidence for the Alcohol Myopia Theory has originated from studies whose participants had specifically to pay attention to a determined stimulus, ignoring others presented in the visual field. In a recent study (Canto-Pereira, David, Machado-Pinheiro, \& Ranvaud, 2007), for instance, volunteers had to respond (by pressing a key - manual reaction time, RT) to luminous points appearing at different positions on the screen while they kept staring at the fixation point in the center of the screen. According to classical works, faster RTs reflects facilitation of visual processing mediated by atten-tion alocation, whereas slower RTs would be observed to stimuli presented in regions out of the attentional focus (Posner, 1980; Rizzolatti, Riggio, Dascola, \& Umilta, 1987). Participants were asked to attend simultaneously to two regions located on the right and left sides of the visual field (divided attention), while ignoring the central fixation point. Volunteers were divided into two groups: intoxicated and non-intoxicated. The alcohol intoxication group received a moderate dose of alcohol $(0.4 \mathrm{~g} / \mathrm{kg}$ of alcohol) in order to reach the blood alcohol concentration (BAC) of .08\%. Trials initiated 25 minutes after the alcohol consumption had finished (this ingestion should occur at a maximum period of 5 minutes). The main result of this study is shown in Figures $1 \mathrm{~A}$ and 1B. The different gray tones observed in both figures reflect the latency of manual responses to stimuli located in different regions of the computer screen (left and right visual field). Brighter tones represent regions where faster RTs were observed, reflecting attentional allocation. From this type of analysis called "geo-statistics" (stimulus representation of RTs at different sites within a colourscale range), it was possible to estimate the spatial distribution of attention during task performance. As can be observed in Figure 1A, non-intoxicated individuals succeeded in paying attention to both right and left regions of the computer screen, ignoring the center. On the other hand, intoxicated individuals were not able to ignore the fixation point, since they still kept their attention in the center of the screen, although they had been instructed to pay attention to periphery only (Figure 1B).

The results described above can be interpreted according to the Alcohol Myopia Theory. According to it, attentional capacity would be reduced in intoxicated individuals, thus making it difficult to process and select environmental stimuli adequately. In addition, the theory postulates that the amount of distractive stimulus processed largely depends on the relevant task difficulty. In that study (Canto-Pereira et al., 2007), volunteers should perform a simple visual detection task. One can note that although participants were asked to pay attention to lateral regions of the display, the fixation point at the center of the screen represented a distractive stimulus, which should be ignored. Because the target task was not demanding, the distractive stimulus ended up strongly interfering with the performance, leading to a failure in inhibiting the fixation point processing by the intoxicated group. In other words, a less-demanding attentional task allowed a greater amount of resources available for the processing of a distractive stimulus (fixation point), thus interfering with attention allocation during the detection of target stimuli (Canto-Pereira et al., 2007; David et al., 2005). 

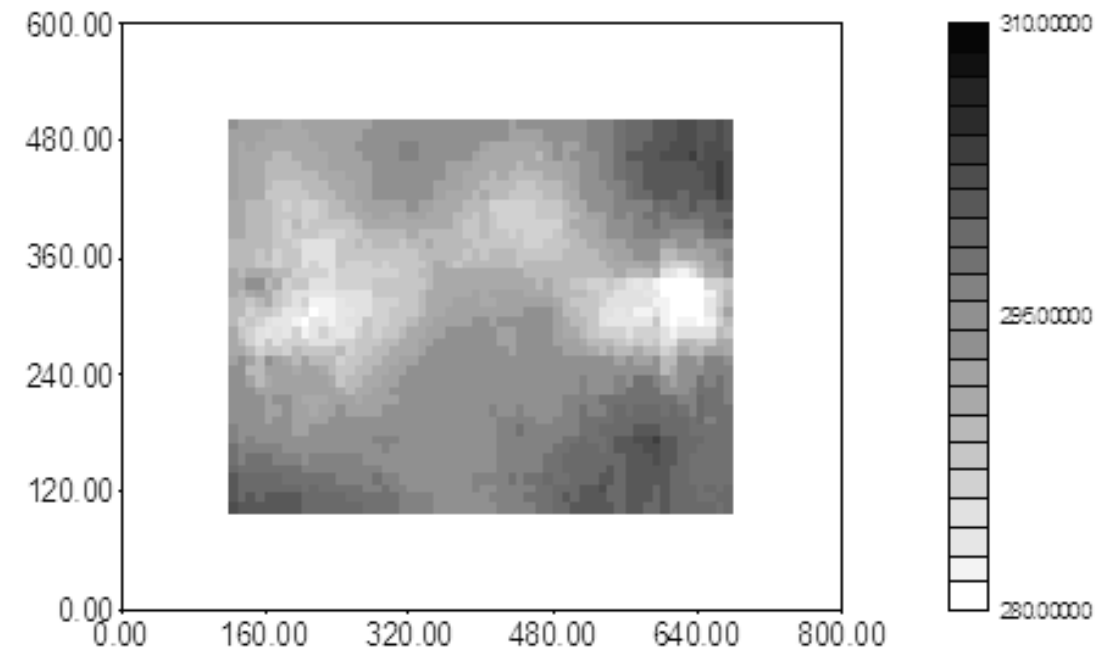

Figure 1A. Distribution of spatial attention in non-intoxicated participants Note. Non-intoxicated participants: Geo-statistic map showing reaction time (RT) collected from an area of $120 \times 680$ pixels in the abscissa axis and $100 \times 500$ pixels in the ordinate axis. Participants were asked to pay attention to both left and right sides of the display and ignore the fixation point at the center. Light areas correspond to faster reaction times, thus indicating the positions where attention was predominantly allocated (adapted from CantoPereira et al., 2007, p. 11).
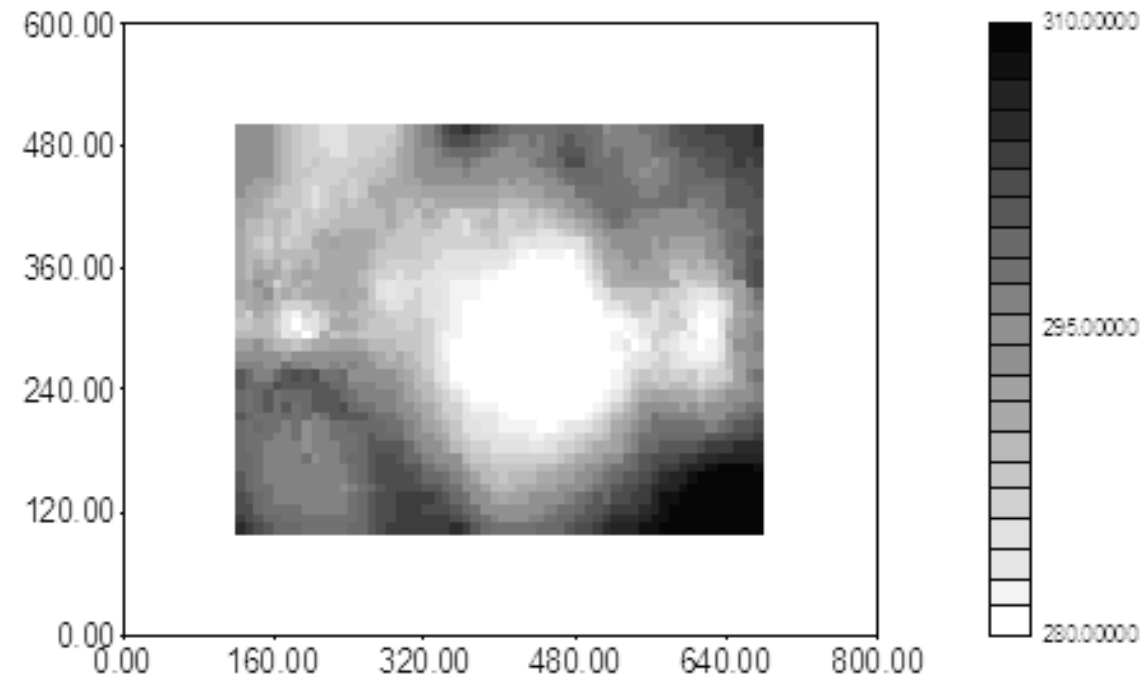

Figure $1 B$. Distribution of spatial attention in intoxicated participants Note. Intoxicated participants: Geo-statistic map showing reaction time (RT) collected from an area of $120 \times 680$ pixels in the abscissa axis and $100 \times 500$ pixels in the ordinate axis. Participants were asked to pay attention to both left and right sides of the display and ignore the fixation point at the center. Light areas correspond to faster reaction times, thus indicating the positions where attention was predominantly allocated (adapted from CantoPereira et al., 2007, p. 11).

On the other hand, alcohol seems to reduce the interference of distractive stimuli during the performance of high-load target tasks. This reduction in the processing of distractive stimuli during the execution of a concomitant high-demanding cognitive task has already been observed in other studies (Curtin, Patrick, Lang, Cacioppo,
\& Birbaumer, 2001; Erthal et al., 2005). Curtin and colleagues (2001) investigated the emotion-cognition interaction and showed that reduced attentional resources observed during alcohol intoxication were able to attenuate the fear response. The referred study used the conditioning model to show that alcohol could decrease 
the fear response (evaluated through startle reflex). This attenuation was only observed under a highly demanding cognitive task, in which the processing of threatening stimuli occurred simultaneously to a relevant visual-motor task. The change in emotional behavior (fear reduction) resulting from acute alcohol intoxication can illustrate this model of cognition-emotion interaction, where alcohol seems to influence the emotional processing through its effects on cognitive processing.

Another study investigated the role of cognitive mechanisms as mediators of alcohol effects on emotion (Erthal et al., 2005). After alcohol ingestion, volunteers were asked to discriminate the relative orientation between two bars displayed in the peripheral visual field (Figure
2). Simultaneously, a distractive picture (neutral or emotional) was centrally presented between the bars. The level of difficulty regarding the target task (discriminating the bars) increased progressively as the difference in relative orientation between the bars was smaller. Therefore, the difference in bar orientation could be of $90^{\circ}, 24^{\circ}$ and $12^{\circ}$, respectively, for easy, intermediate, and hard tasks. The premise was that the more difficult the target task was, the more processing resources should be allocated, thus decreasing the resources available for distractive processing. The results showed that emotional pictures slowed RT during the performance of the easy and intermediate tasks when individuals were intoxicated. However, such emotional interference was abolished in the hard task.

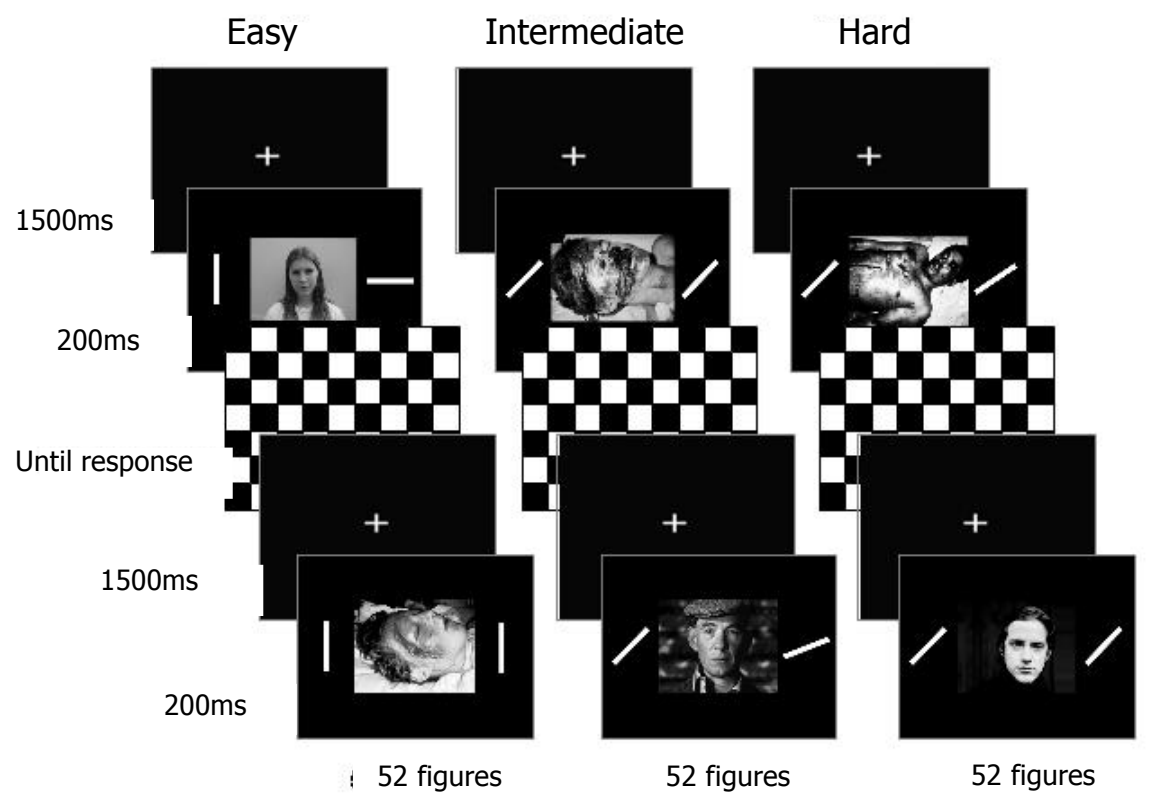

Figure 2. Experimental paradigm

Note. The fixation point was initially presented $(1500 \mathrm{~ms})$ and then a central picture was shown simultaneously with two peripheral bars $(200 \mathrm{~ms})$. A checkerboard mask was displayed for $1500 \mathrm{~ms}$ or until a response was emitted. Participants were asked to ignore the central picture and pay attention to the peripheral bars, pressing one of the two keys (as quickly and accurately as possible) if the bars were equal or different (from Erthal, Oliveira, Machado-Pinheiro, Pessoa, \& Volchan, 2004, p. 35).

This pattern of results provides further evidence that during execution of high-demanding cognitive tasks and under alcohol influence, there is a reduction in the processing of distractive emotional stimuli. Within this context, one can conclude that alcohol effects were decisive for the elimination of the emotional interference, since sober subjects still exhibited a delay in reaction time even during execution of the same "hard" task, that is, under the same load and the same distractive emotional pictures (Erthal et al., 2004; Erthal et al., 2005). In fact, the referred study provides further evi- dence that corroborates the Alcohol Myopia Theory (Josephs \& Steele, 1990; Steele \& Josephs, 1988; and Wester, Bocker, Volkerts, Verster, \& Kenemans, 2008) by showing that emotional stimuli seem to lose their relevance under alcohol intoxication in the presence of a relevant demanding cognitive task, thus failing in capturing attention automatically. Therefore, the attenuation of the processing of emotional pictures was mediated by the alcohol effects on cognition.

The studies described above support the Alcohol Myopia Theory (Josephs \& Steele, 1990) by providing 
evidence that alcohol seems to attenuate the emotional processing bi-directionally, increasing or decreasing the processing of distractive stimuli as a function of the cognitive demand of the target task/situation. This means that the processing of a distractive stimulus may be either attenuated (Erthal et al., 2005) or exacerbated (CantoPereira et al., 2007) depending on the presence or absence of a demanding attentional task.

The approach above discussed also helps to explain the presence of anxiolytic and, paradoxically anxiogenic, effects observed in the study conducted by Josephs and Steele (1990) following alcohol consumption. Therefore, relying again on their classic study (Josephs \& Steele, 1990), the anxiety related to speech presentation could be reduced or exacerbated depending on the presence or absence of external demands. The intoxicated volunteers who performed the moderate demanding task showed a decreased anxiety level, whereas those who performed no such task exhibited higher anxiety levels. This discrepancy in the results observed in intoxicated participants points to the key role played by attentional allocation as a mediator of anxiolytic or anxiogenic effects observed under a given alcohol concentration. In the absence of a demanding task, it is probable that the intoxicated volunteers have focused their attention on the imminent stressful event (speech presentation) and thus anxiety level increased as a result.

\section{Risky Behavior Under the Perspective of Alcohol Myopia}

The concept of alcohol myopia can be applied to and interpreted within the context of daily-life situations. It is particularly interesting to evaluate the impact of this theory on public health issues, especially those related to risky behaviors. The theoretical construct of alcohol myopia can be interpreted in the light of daily-life situations associated to alcohol consumption. For instance, in transit situations in which the main task is to safely drive the vehicle, individuals should be capable of detecting possible relevant stimuli appearing unexpectedly (e.g. a child suddenly crossing in front of the car). Thus, driving can be considered a divided attentional task, which involves paying attention to relevant and unexpected (distractive) stimuli (Clifasefi, Takarangi, \& Bergman, 2006; Wester et al., 2008). In the case of an intoxicated individual, whose attentional capacity is reduced, sufficient resources would not be available to process new and important stimuli occurring in the scene, such as the child suddenly crossing the street. This diminished availability of resources for processing unexpected stimuli would increase, therefore, the likelihood of accidents and collisions (MacDonald, Zanna, \& Fong, 1995).

A recent study also provided evidence that aggressive behavior under alcohol intoxication is mediated by factors associated to the attention-allocation model encompassed by the Alcohol Myopia Theory (Giancola \& Corman, 2007). In the study, aggression was tested in the laboratory by means of electrical shocks that could be received by or applied to a fictitious opponent. Volunteers took part in a competitive reaction-time game in which the faster contestant applied an electrical shock to the opponent. In tasks in which the fictitious opponent was faster, the volunteer received electrical shocks. The level of physical aggression was measured by both the intensity and the duration of electrical shocks being applied. While the volunteers took part in the experiment, they also performed a simultaneous task: they had to pay attention to a matrix of squares on the computer screen and remember the sequence in which those squares were illuminated. The results showed that this moderately-demanding distractive task reduced aggression in intoxicated volunteers suggesting, again, a relationship between cognitive processing and behavior (aggression) under alcohol intoxication.

We are constantly under influence of internal or external cues or stimuli which affect our behavior. Some stimuli can trigger the inhibitition of inadequate behaviors, based on its posible negative outcomes. Also, there are cues which emphasizes the positive aspects of our actions, such as immediate pleasure, potentially leading to impulsive behaviors (George, Rogers, \& Duka, 2005). According to some authors (Giancola \& Corman, 2007; MacDonald, Fong, Zanna, \& Martineau, 2000; and MacDonald, MacDonald, et al., 2000), under situations involving competition between those cues, alcohol intoxication seems to restrict the cognitive capacity, and attentional resources are preferentially allocated to more relevant or immediate stimuli. Therefore, when there is conflict between environmental cues resulting in aggression and those inhibiting aggressive behavior, which in general are less relevant, the processing of the former would be privileged and the latter ignored. Then, intoxicated individuals seem to make a decision upon their actions through more immediate and explicit information at the expenses of the judgement on the future consequences of their acts (Ito, Miller, \& Pollock, 1996; MacDonald, Fong, et al., 2000). As a result, according to the attention-allocation model of the alcohol myopia, attention is focused on more relevant and provoking cues at the expense of more subtle inhibitory cues of aggressive behavior in hostile environments.

In addition to the violent behavior, the alcohol consumption among adolescents is also related to risky sexual behavior (Davis et al., 2007; George et al., 2008; Hendershot \& George, 2007; MacDonald, Fong, et al., 2000; MacDonald, MacDonald, et al., 2000; and MacDonald et al., 1996). Intoxicated volunteers are more susceptible to environmental cues inducing to unsafe sexual practice compared to sober individuals. Intoxicated individuals seem to attend to the stimuli that provide them with immediate pleasure so that environmental cues are 
ignored, thus leading to the negative outcomes involving the unsafe sex (Hendershot \& George, 2007; and MacDonald, MacDonald, et al., 2000). A review reported an increase in the number of studies related to the relationship between alcohol consumption and risky sexual practice in the past three decades (Cerwonka, Isbell, $\&$ Hansen, 2000). The review reported less use of condoms among individuals who associate alcohol with sexual practice. Still within this context, it was observed that intoxicated individuals think that driving for a short time even under alcohol effect is less negative, thus demonstrating that the attenuation in the processing of inhibitory cues under alcohol intoxication can indeed affect their judgement capacity (George et al., 2005).

Taken together, these findings are important to guide public health policies aimed to reduce the incidence of risky behaviors. The proposed interventions involve advertising campaigns which emphasize the negative consequences of risky behaviors, mainly in places like pubs and night clubs which are associated with alcohol consumption (Ito et al., 1996; MacDonald, Fong, et al., 2000). This intervention aims to increase the efficiency of inhibitory cues, helping to reduce risky behaviors even in intoxicated individuals. In fact, there is evidence that intoxicated individuals are able to increase the processing of inhibitory cues, which highlights the negative consequences of unsafe sex, when these cues are really emphasized (MacDonald, Fong, et al., 2000). In short, the Alcohol Myopia Theory points out the influence of the disruptive effects of alcohol consumption on both cognitive and emotional processing, emphasizing the critical role of context to determine the variability of alcohol effects on behavior.

\section{Conclusions}

The literature on alcohol effects as a predisposing factor for risky, aggressive and impulsive behaviors points to possible underlying attentional mechanisms, as suggested by the Alcohol Myopia Theory. The traditional interpretation of the pure pharmacological effects of alcohol on the central nervous system can be complemented by the attention-allocation model. Specifically, converging evidence enhances the mediating effects of attention and cognition on the emotional processing in intoxicated individuals, validating such a theory. Comprehension of such mechanisms provides inputs for a discussion on the scientifically-supported public health propositions aimed at preventing problems related to acute alcohol intoxication.

\section{References}

Bartholow, B. D., Pearson, M., Sher, K. J., Wieman, L. C., Fabiani, M., \& Gratton, G. (2003). Effects of alcohol consumption and alcohol susceptibility on cognition: A psychophysiological examination. Biological Psychology, 64, 167-190.
Canto-Pereira, L. H., David, I. P. A., Machado-Pinheiro, W., \& Ranvaud, R. D. (2007). Effects of acute alcohol intoxication on visuospatial attention. Human and Experimental Toxicology, 26, 311-319.

Casbon, T. S., Curtin, J. J., Lang, A. R., \& Patrick, C. J. (2003). Deleterious effects of alcohol intoxication: Diminished cognitive control and its behavioral consequences. Journal of Abnormal Psychology, 112, 476-487.

Cerwonka, E. R., Isbell, T. R., \& Hansen, C. E. (2000). Psychosocial factors as predictors of unsafe sexual practices among young adults. AIDS Education and Prevention: Official publication of the International Society for AIDS Education, 12, 141-153.

Clifasefi, S. L., Takarangi, M. K. T., \& Bergman, J. S. (2006). Blind drunk: The effects of alcohol on inattentional blindness. Applied Cognitive Psychology, 20, 697-704.

Curtin, J. J., Lang, A. R., Patrick, C. J., \& Stritzke, W. G. (1998). Alcohol and fear-potentiated startle: The role of competing cognitive demands in the stress-reducing effects of intoxication. Journal of Abnormal Psychology, 107, 547-557.

Curtin, J. J., Patrick, C. J., Lang, A. R., Cacioppo, J. T., \& Birbaumer, N. (2001). Alcohol affects emotion through cognition. Psychological Science, 12, 527-531.

David, I. P. A., Volchan, E., Menchise, C., Alfradique, I., Oliveira, L., \& Machado-Pinheiro, W. (2005). Influência de manipulações temporais sobre a magnitude do Efeito Stroop. Arquivos Brasileiros de Psiquiatria, Neurologia e Medicina Legal, 99, 11-17.

Davis, K. C., Hendershot, C. S., George, W. H., Norris, J., \& Heiman, J. R. (2007). Alcohol's effects on sexual decision making: An integration of alcohol myopia and individual differences. Journal of Studies on Alcohol and Drugs, 68, 843-851

Donohue, K. F., Curtin, J. J., Patrick, C. J., \& Lang, A. R. (2007). Intoxication level and emotional response. Emotion, 7, 103-112.

Eckdart, M., File, S., Gessa, G. L., Grant, K. A., Guerri, C., Hoffman, P., et al. (1998). Effects of moderate alcohol consumption on the central nervous system. Alcoholism: Clinical and Experimental Research, 22(5), 998-1040.

Erthal, F., Oliveira, L., Machado-Pinheiro, W., Pessoa, L., \& Volchan, E. (2004). Captura da atenção por estímulos emocionais. Paidéia: Cadernos de Psicologia e Educação, 14, 35-44.

Erthal, F. S., Oliveira, L., Mocaiber, I., Pereira, M. G., Machado-Pinheiro, W., Volchan, E., et al. (2005). Load-dependent modulation of affective picture processing. Cognitive Affective and Behavioral Neuroscience, 5, 388-395.

George, S., Rogers, R. D., \& Duka, T. (2005). The acute effect of alcohol on decision making in social drinkers. Psychopharmacology, 182, 160-169.

George, W. H., Davis, K. C., Norris, J., Heiman, J. R., Stoner, S. A., Schacht, R. L., et al. (2008). Indirect effects of acute alcohol intoxication on sexual risk-taking: The roles of subjective and physiological sexual arousal. Archives of Sexual Behavior, 38(4), 498-513.

Giancola, P. R., \& Corman, M. D. (2007). Alcohol and aggression: A test of the attention-allocation model. Psychological Science, 18, 649-655.

Gilman, J. M., Ramchandani, V. A., Davis, M. B., Bjork, J. M., \& Hommer, D. W. (2008). Why we like to drink: A functional magnetic resonance imaging study of the rewarding and anxiolytic effects of alcohol. Journal of Neuroscience, 28, 4583-4591. 
Hendershot, C. S., \& George, W. H. (2007). Alcohol and sexuality research in the AIDS era: Trends in publication activity, target populations and research design. AIDS and Behavior, 11, 217-226.

Herzog, T. A. (1999). Effects of alcohol intoxication on social inferences. Experimental and Clinical Psychopharmacology, 7, 448-453.

Ito, T. A., Miller, N., \& Pollock, V. E. (1996). Alcohol and aggression: A meta-analysis on the moderating effects of inhibitory cues, triggering events, and self-focused attention. Psychological Bulletin, 120, 60-82.

Josephs, R. A., \& Steele, C. M. (1990). The two faces of alcohol myopia: Attentional mediation of psychological stress. Journal of Abnormal Psychology, 99, 115-126.

Levenson, R. W., Sher, K. J., Grossman, L. M., Newman, J., \& Newlin, D. B. (1980). Alcohol and stress response dampening: Pharmacological effects, expectancy, and tension reduction. Journal of Abnormal Psychology, 89, 528-538.

MacAndrew, C., \& Edgerton, R. B. (1969). Drunken comportment: A social explanation. Chicago: Aldine.

MacDonald, T. K., Fong, G. T., Zanna, M. P., \& Martineau, A. M. (2000). Alcohol myopia and condom use: Can alcohol intoxication be associated with more prudent behavior? Journal of Personality and Social Psychology, 78, 605-619.

MacDonald, T. K., MacDonald, G., Zanna, M. P., \& Fong, G. T. (2000). Alcohol, sexual arousal, and intentions to use condoms in young men: Applying alcohol myopia theory to risky sexual behavior. Health Psychology, 19, 290-298.

MacDonald, T. K., Zanna, M. P., \& Fong, G. T. (1995). Decisionmaking in altered states: Effects of alcohol on attitudes toward drinking and driving. Journal of Personality and Social Psychology, 68, 973-985.

MacDonald, T. K., Zanna, M. P., \& Fong, G. T. (1996). Why common sense goes out the window: Effects of alcohol on intentions to use condoms. Personality and Social Psychology Bulletin, 22, 763-775.

Monahan, J., \& Lannutti, P. (2000). Alcohol as social lubricant: Alcohol Myopia Theory, Social self-esteem and social interaction. Human Communication Research, 26(2), 175-202.
Phillips, J. P., \& Giancola, P. R. (2008). Experimentally induced anxiety attenuates alcohol-related aggression in men. Experimental and Clinical Psychopharmacology, 16, 43-56.

Posner, M. I. (1980). Orienting of attention. Quarterly Journal of Experimental Psychology, 32, 3-25.

Posner, M. I. (1995). Attention and cognitive neuroscience: An overview. In M. S. Gazzaniga (Ed.), The cognitive neurosciences (pp. 615-624). Cambridge, MA: MIT Press.

Post, R. B., Chaderjian, M. R., \& Maddock, R. J. (2000). Effects of alcohol on exogenous precueing of attention. Journal of Studies on Alcohol, 61, 232-238.

Ramchandani, V.A., Bosron, W. F., \& Li, T. K. (2001). Research advances in ethanol metabolism. Pathologie-Biology (Paris), 49, 676-682.

Rizzolatti, G., Riggio, L., Dascola, I., \& Umilta, C. (1987). Reorienting attention across the horizontal and vertical meridians: Evidence in favor of a premotor theory of attention. Neuropsychologia, 25, 31-40.

Sayette, M. A. (1993). An appraisal-disruption model of alcohol's effects on stress responses in social drinkers. Psychological Bulletin, 114, 459-476.

Steele, C. M., \& Josephs, R. A. (1988). Drinking your troubles away. II: An attention-allocation model of alcohol's effect on psychological stress. Journal of Abnormal Psychology, 97, 196-205.

Steele, C. M., \& Josephs, R. A. (1990). Alcohol myopia. Its prized and dangerous effects. The American Psychologist, 45, 921-933.

Wester, A. E., Bocker, K. B. E., Volkerts, E. R., Verster, J. C., \& Kenemans, J. C. (2008). Event-related potentials and secondary task performance during simulated driving. Accident Analysis and Prevention, 40(1), 1-7.

Zeichner, A., \& Pihl, R. O. (1980). Effects of alcohol and instigator intent on human aggression. Journal of Studies on Alcohol, 41, 265-276.
Recebido: 05/03/2009 $1^{a}$ revisão: $21 / 10 / 2009$ $2^{a}$ revisão: $19 / 03 / 2010$ Aceite final: 05/05/2010 